\title{
MODIFIED EXTRACTION GEOMETRY IN A RADIO-FREQUENCY ION SOURCE
}

\author{
I. KISS, E. KOLTAY and P. BORNEMISZA-PAUSPERTL \\ Institute of Nuclear Research of the Hungarian \\ Academy of Sciences. P.o.b.51, 4001 Debrecen, Hungary
}

\begin{abstract}
Résumé. - Dans notre présent travail nous proposons de démontrer qu'on dispose d'une série de preuves pour l'utilisation de la géométrie d'extraction, élaborée par Bayly et Ward, dans les sources d'ions du type à haute fréquence. Au cours de nos mesures, nous avons comparé la variante de cette méthode dû à Thonemann-Harrison à celui de Schmidt-Eyrich du point de vue des paramètres de fonctionnement et des caractéristiques du faisceau. Comme paramètre caractérisant le fonctionnement de la source d'ions, nous avons utilisé le courant, la consommation du gaz, le spectre de masse et la courbe d'émittance.
\end{abstract}

\begin{abstract}
This paper is to show that a number of plausible arguments supporting the use of Bayly and Ward's extraction geometry in radio-frequency ion source can be put forward. The ThonemannHarrison and the Schmidt-Eyrich version of this method have been compared in a series of measurements from the points of view of working parameters and beam characteristics. Current, gas supply rate, mass spectrum and emittance curve have been used to characterize the performance of the sources.
\end{abstract}

1. Introduction. - Radio-frequency ion sources are widely used in direct voltage accelerators owing to their long life and good beam characteristics. Satisfactory working conditions however can only be obtained by solving a number of physical and technological problems. According to the different realization of beam extraction existing radio-frequency ion sources can be devided into two groups.

In the most often used version developed by Thonemann the extraction potential is given between the extraction probe at the top of the discharge bottle and the tip with a narrow extraction canal. An appropriately shaped insulator made of quartz plays an important role in determining the extraction condition of the source. In this paper the commercial ion sources HVEC-C-SO-173 [1] and IONEX-320 [2] will be considered as outstanding representatives of this group.

A probeless bottle is used in the case of the second version by Bayly and Ward [3]. Here the extraction voltage is put on a pair of extraction electrodes situated at the exit opening of the bottle. This idea was followed in a number of investigations (Harrison [4], Thonemann and Harrison [5], Schmidt and Eyrich [6], NIIEFA [7], Nagy [8] Pásztor [9]) aiming at the development of the new version of radio-frequency ion sources that meets the requirements of electrostatic accelerators.

A number of arguments can be put forward in favour of a probeless extraction system: a. due to the absence of a probe the bottle of the source is of pure quartz construction, no metal-toglass seals are necessary,

b. contrary to the case with the extraction probe in which the plasma is essentially at the probe potential in the present case the plasma remains at the potential of the base plate. Consequently bottle damages often made by secondary electrons accelerated toward the probe in the dark space near the extraction tube are practically absent here. The majority of the secondary electrons are collected by the extraction anode situated in the immediate vicinity of the canal. At the same time the radial electrical stress of the bottle wall, which in the Thonemann case corresponds to the difference between extraction potential and the anode voltage of the oscillator, will be lowered to the value defined by the anode voltage only. Consequently no bottle punctures will appear owing to breakdowns through the wall.

c. The extraction field generated here by well shaped metal electrodes is only slightly influenced by the presence of the quartz cup which screens the anode and is to be used for reducing ion recombination on metal surfaces exposed to the discharge. Consequently, working conditions can be expected to be stable and not strongly depending on the cleanness and exact shaping of the quartz surfaces.

The above mentioned features of the probless extraction seem to facilitate the realization of a 
reliable ion source on this basis. The striking simplicity can be considered as a major advantage in the case of home made accelerators where delicate technological procedures are to be avoided in producing the construction elements. This was our reason for using different versions of probeless extraction of Bayly and Ward in a 5 MV Van de Graaff accelerator [10]. In what follows experimental data are presented to show that the normal requirements of electrostatic accelerators can be fullfilled by using this type of radio-frequency source.

2. Ion source assembly, characteristic data. - The technical details of the ion sources now being used in our electrostatic generators as well as in a moderate current neutron generator of the Institute are shown in figures 1 and 2. Figure 1 schematically shows the structure of the ion source while figure 2 presents the different electrode configurations (referred to as version (a), (b-1), (b-2) and (c), respectively,) tested in the present work. Due to the presence of the insulating cylinder between the extraction electrodes the gas pressure in the bottle drops along the canal of low vacuum conductance to the level of the high vacuum of the acceleration tube. Special care must be taken of the coaxiality of extraction anode and cathode with the focusing lens.

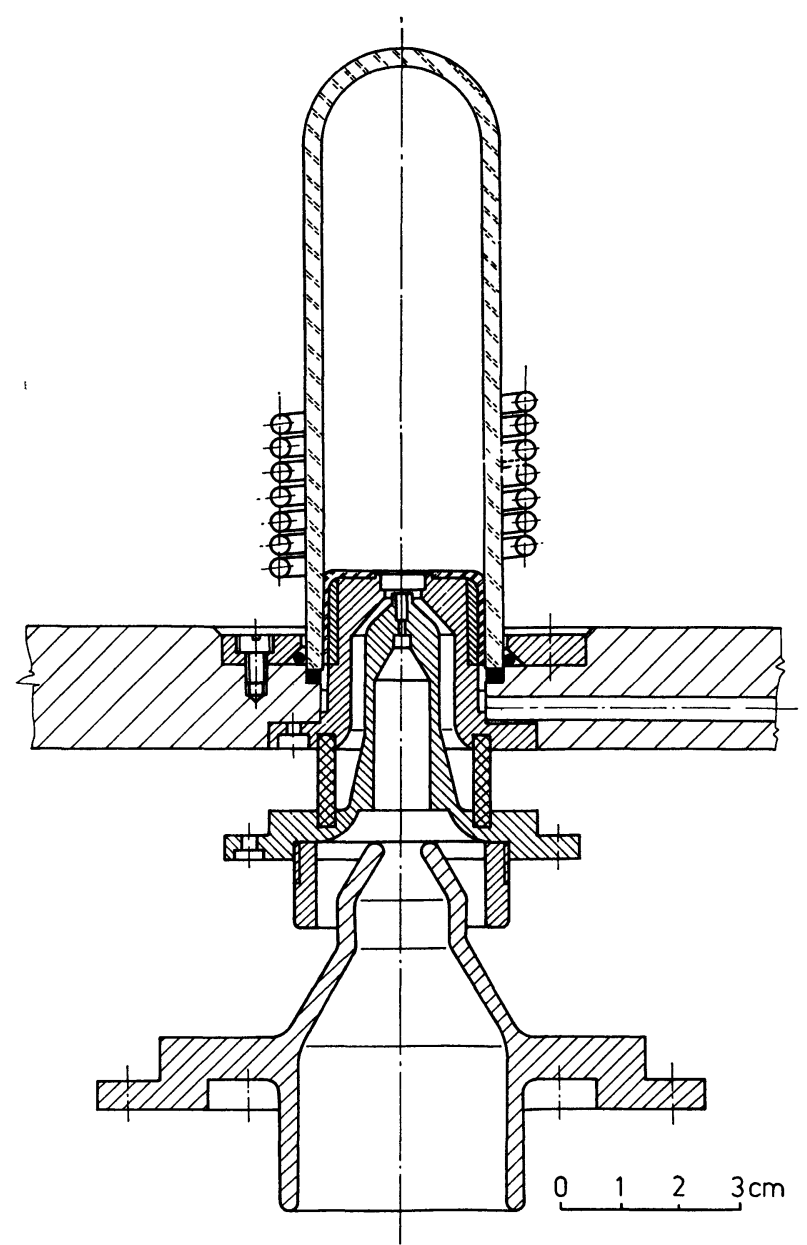

Fig. 1. - The ion source with replaceable extraction electrodes.
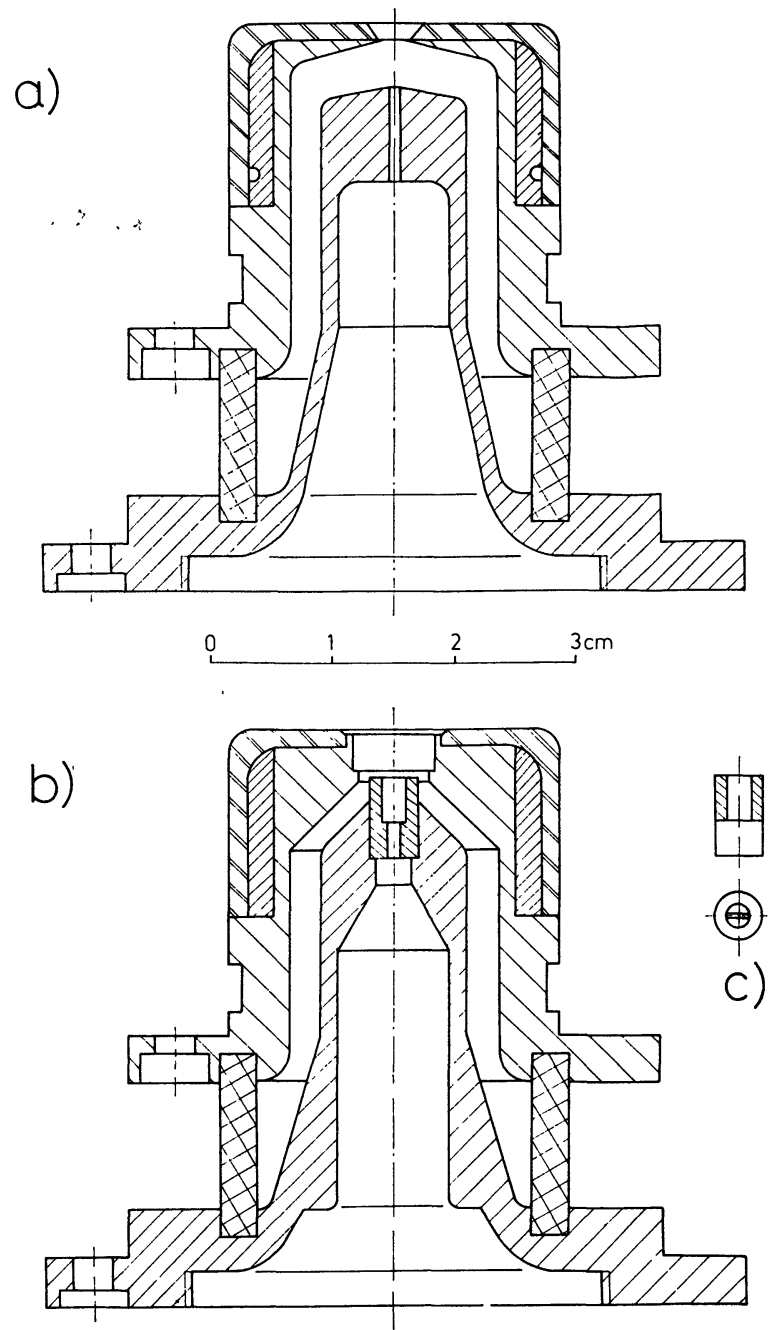

FIG. 2. - Electrode configurations tested in the present work.

Version (a) [8] which follows the construction of Thonemann and Harrison [6] has been succesfully used in a compact 1 MV Van de Graaff accelerator [11] where the low conductance of the acceleration tube limited the beam intensity to a level of a few microampere available at a gas supply rate of $1 \mathrm{~cm}^{3} / \mathrm{h}$. The penetration of the extraction field into the discharge volume is strongly limited here by the small diameter of the extraction diaphragm realized by the anode. The beam intensity remained quite low at different lengths and diameters of the canal. The dependence of maximum beam intensity and gas supply rate on the geometrical parameters of the extraction lens can be seen in table I. The lower curve in figure 3 shows this dependence graphically. The different points were taken with electrodes of different geometrical parameters, the indicated current values are the maxima obtained at optimum extraction and focusing voltages. The labelled points indicate data corresponding to Thonemann sources described in [1] and [2]. As it is clearly shown by the comparison version (a) can not be considered as a suitable construction except for low beam intensities. Furthermore, 
TABLE I

Measured data of gas supply rate and beam intensity for different electrode dimensions (hydrogen beam)

\begin{tabular}{|c|c|c|c|c|c|c|}
\hline \multirow[b]{2}{*}{$\begin{array}{l}\text { anode } \\
\text { opening } \\
\text { mm }\end{array}$} & \multirow{2}{*}{$\begin{array}{c}\text { Diameter } \\
\text { cathode } \\
\text { entrance } \\
\text { mm }\end{array}$} & \multirow[b]{2}{*}{$\begin{array}{c}\text { cathode } \\
\text { canal } \\
\mathrm{mm}\end{array}$} & \multicolumn{2}{|c|}{ Length } & \multirow{2}{*}{$\begin{array}{l}\text { Gas } \\
\text { supply } \\
\text { rate } \\
\mathrm{cm}^{3} / \mathrm{h}\end{array}$} & \multirow[b]{2}{*}{$\begin{array}{l}\text { Ion } \\
\text { current } \\
\mathrm{mA}\end{array}$} \\
\hline & & & $\begin{array}{c}\text { cathode } \\
\text { entrance } \\
\mathrm{mm}\end{array}$ & $\begin{array}{c}\text { cathode } \\
\text { canal } \\
\mathrm{mm}\end{array}$ & & \\
\hline \multicolumn{7}{|c|}{ version (a) } \\
\hline 1.4 & - & 0.7 & - & 7 & 1.1 & 0.045 \\
\hline 1.4 & - & 1.0 & - & 8 & 1.9 & 0.052 \\
\hline 1.4 & - & 1.2 & - & 7 & 4.3 & 0.057 \\
\hline 1.8 & - & 1.2 & - & 7 & 6.7 & 0.165 \\
\hline 1.8 & - & 1.6 & - & 8 & 8.4 & 0.145 \\
\hline 2.1 & - & 1.2 & - & 7 & 6.7 & 0.190 \\
\hline 2.1 & - & 1.6 & - & 8 & 11.0 & 0.180 \\
\hline 2.1 & - & 1.2 & - & 5 & 7.6 & 0.210 \\
\hline 2.1 & - & 1.6 & - & 5 & 15.5 & 0.225 \\
\hline 3.0 & - & 2.0 & - & 5 & 25 & 0.340 \\
\hline 3.0 & - & 2.2 & - & 5 & 34 & 0.410 \\
\hline 3.0 & - & 2.0 & - & 4 & 35 & 0.360 \\
\hline 4.0 & - & 3.0 & - & 4 & 60 & 1.500 \\
\hline \multicolumn{7}{|c|}{ version (b) } \\
\hline 6.0 & 1.5 & 0.8 & 4 & 3 & 4 & 0.220 \\
\hline 6.0 & 1.5 & 0.9 & 4 & 3 & 4.7 & 0.235 \\
\hline 6.0 & 1.5 & 1.0 & 4 & 3 & 5.5 & 0.450 \\
\hline 6.0 & 1.5 & 1.2 & 4 & 3 & 7.8 & 1.600 \\
\hline 6.0 & 1.5 & 1.4 & 4 & 3 & 11 & 2.400 \\
\hline 6.0 & - & 1.6 & - & 7 & 14 & 3.000 \\
\hline 6.0 & - & 1.8 & - & 7 & 28 & 3.900 \\
\hline
\end{tabular}

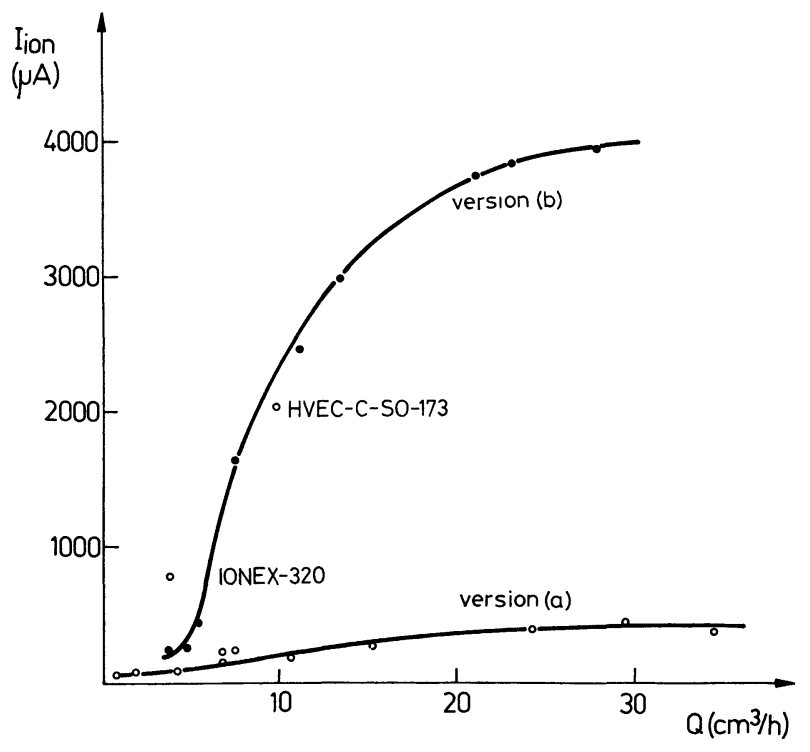

FIG. 3. - Maximum beam intensity vs. gas supply rate for different extraction geometries. For notation see figure 2.

the beam parameters were found to be quite sensitive on the cleanness and exact shaping of the quartz cup. This feature is a drawback from the point of view of stable working conditions.
A modification resulting in version (b) has been performed in order to improve the extraction properties of the source. The electrode configuration developed by Schmidt and Eyrich [6] seemed to solve the above problem by the aid of its extraction geometry fully defined in the paraxial region by extraction electrodes only. The intense extraction effect can be visualized by running the source at low gas pressure. Under such conditions a cornet-shaped deformation of the discharge pointing at the extraction canal appears. The data contained by table I and figure 3 exhibit a considerable improvement of the characteristics.

In the case of the new configuration the area of metal surface exposed to the discharge increased a lot because of the unscreened cathode tip entering the gas space. Consequently, an increased effect of recombination partly resulting in the increase of the molecular beam component could be expected. In order to get a guess on the magnitude of this effect mass analyses have been performed on the direct hydrogen beam of the $1 \mathrm{MV}$ electrostatic accelerator [11] equipped with sources of both version (a) and (b). The measurements have been performed by the aid of the Rutherford scattering. The splitting up of the $\mathrm{H}_{2}^{+}$and $\mathrm{H}_{3}^{+}$molecules in the Coulomb field of target nuclei produces 
protons entering the scattering process with half and third of the original energy, respectively.

The energy spectra of the scattered particles can be transformed in mass spectra using the energy dependence of the scattering cross section. The results presented in figure 4 indicate that the atomic component of the beam remains at the high value of $81 \%$ in the case of version (b).

In an earlier article of the authors [12] it was pointed out that a line shaped beam could advantageously be

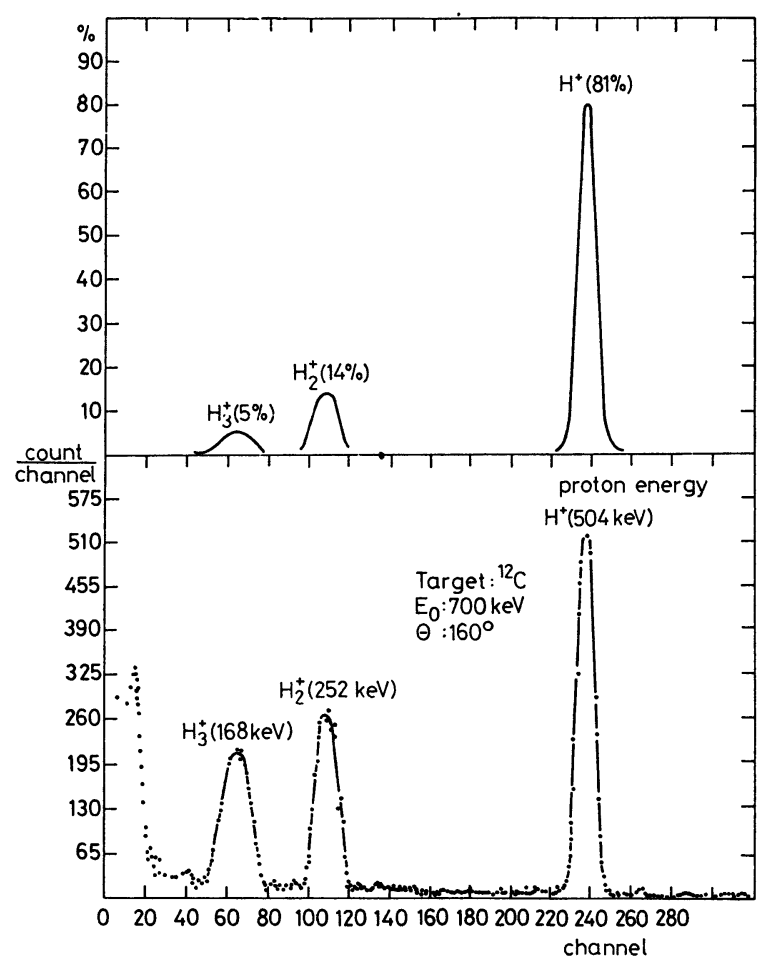

Fig. 4. - Mass spectrum of the beam calculated from energy spectrum of ions scattered on carbon foil. used in a high voltage accelerator under special experimental conditions. There a new electrostatic lens was proposed and described in the first order approximation as a tool for forming line shaped beam. We realizes that the replacable tantalum tip of the extraction canal can easily be shaped such a way that the circular canal will be changed to an opening of rectangular cross section. Version (c) corresponds to an ion source of this character. The line shaped beam has been extracted and accelerated through the whole acceleration tube succesfully in one experiment. No systematic investigation, however, has been carried out concerning the practical application of the line shaped source or of the combination of the source with the quadrupole lens described in [12].

The beam properties can be well represented by the so-called emittance diagrams indicating the phasespace distribution of points corresponding to separate particle trajectories of the beam in a plane perpendicular to the beam axis. Sophisticated electronical devices have been developed for accurate and automatic measuring the emittance curves [13] [14]. For the purpose of a rough demonstration the classical method described in the paper of Conzett and Harvey [15] has been used in the present work. Here transversal coordinates and particle directions are scanned by transmitting the beam through fine holes periodically arranged in a plane perpendicular to the beam and by observing the position and dimensions of beam element spots on a heat sensitive paper sheet placed at a distance from the perforated disc. The measured curves are presented in figure 5 for versions (b-1), (b-2) and (c). The two different ellipses in the case of version (c) correspond to the different beam sizes along transversal coordinate axes parallel and perpendicular to the extraction slit. The emittance values obtained as areas of the ellipses are given in

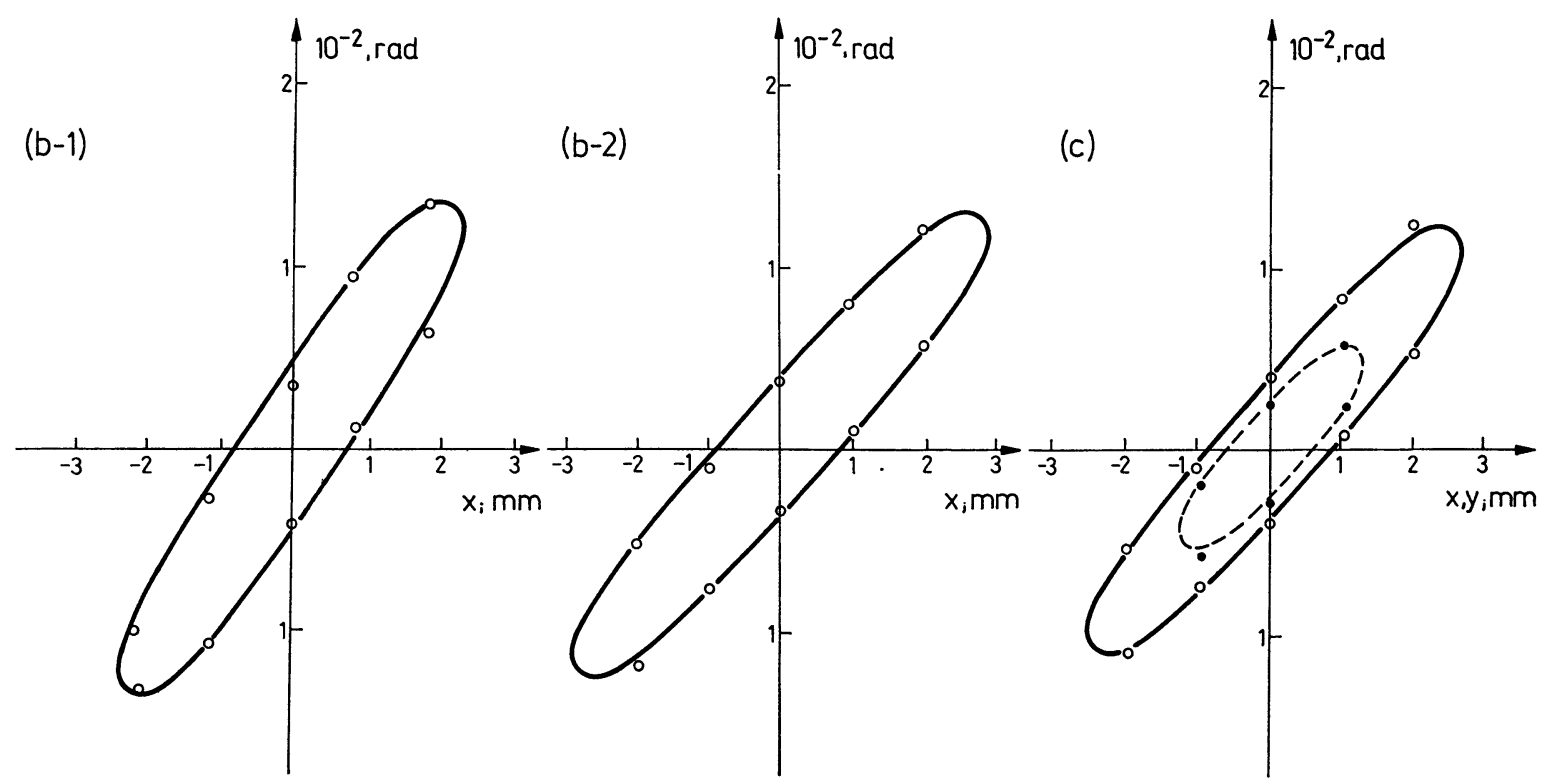

FIG. 5. - Emittance curves for different extraction geometries. For notation see figure 2. 


\section{TABLE II}

\section{List of ion source characteristics}

\begin{tabular}{|c|c|c|c|c|c|c|c|c|c|c|c|c|}
\hline \multirow{5}{*}{ 总 } & \multirow{3}{*}{$\begin{array}{l}\text { TYPE } \\
\text { HVEC - C - } \\
\text { SO - } 173\end{array}$} & \multirow[b]{2}{*}{ Ref. } & \multicolumn{2}{|c|}{$\begin{array}{c}\text { Canal } \\
\text { dimensions } \\
\text { length diam. }\end{array}$} & \multirow{3}{*}{$\begin{array}{l}\text { Geom. } \\
\text { divergence } \\
\text { angle } \\
\text { deg. }\end{array}$} & \multirow{2}{*}{\multicolumn{2}{|c|}{\begin{tabular}{cc}
\multicolumn{2}{c}{ Max. } \\
$i_{\mathrm{H}}$ & $Q_{\mathrm{H}}$ \\
$\mathrm{mA} \mathrm{c} \mathrm{^{3 } / \mathrm { h }}$
\end{tabular}}} & \multirow{2}{*}{$\begin{array}{c}\text { Typical } \\
\text { life } \\
\mathrm{h}\end{array}$} & \multicolumn{3}{|c|}{$\begin{array}{c}\text { Emittance } \\
\text { measured at }\end{array}$} & \\
\hline & & & $\mathrm{mm}$ & $\mathrm{mm}$ & & & & & $\mathrm{keV}$ & $\mathrm{keV}$ & $\mathrm{mA}$ & \\
\hline & & 1 & - & 2.1 & & 2 & 10 & 700 & - & - & - & - \\
\hline & ORTEC- & & 12.5 & 1.2 & \pm 5.5 & - & - & - & - & - & - & - \\
\hline & IONEX - 320 & 2 & 12.5 & 1.6 & \pm 7 & 0.75 & 4 & 175 & 2.7 & 35 & 0.5 & 0.35 \\
\hline & version (a) & 8 & 7.0 & 0.7 & \pm 5.5 & 0.05 & 1 & 700 & - & - & - & - \\
\hline 3 & version $(b-1)$ & & $\begin{array}{l}3.0 \\
4.0\end{array}$ & $\begin{array}{l}1.4 \\
0.7\end{array}$ & \pm 10 & 0.25 & 4 & 600 & 3 & 10 & 0.1 & 0.43 \\
\hline 5 & version $(b-2)$ & & 7.0 & 1.5 & \pm 12 & 3.0 & 11 & 120 & 3 & 10 & 0.12 & 0.48 \\
\hline & version (c) & & 4.0 & 1.4 & $\pm 4 \times 13$ & - & - & - & 3 & 10 & 0.10 & $0.15 \times 0.43$ \\
\hline 8 & (line shaped) & & 3.0 & $0.2 \times 2$ & & & & & & & & \\
\hline
\end{tabular}

table II summarizing the measured characteristic data of the different source versions.

3. Summary. - Radio-frequency ion sources with extraction system of Bayly and Ward have been found to be simple and reliable tools for being used in elec- trostatic accelerators. The modified extraction electrodes of Schmidt and Eyrich have given characteristic data similar to those obtained in the case of Thonemann probe extraction. Probeless bottle construction and replaceable cathode tips make the realization of the source easy and cheep.

\section{References}

[1] High Voltage Engineering (Europa) N. V. Data Sheet HV-A6021.

[2] General Ionex Corporation, Ion Source Selection Data.

[3] Bayly A. J., Ward A. G., Can. J. Res. 26.A. (1948) 69.

[4] Harrison E. R., J. Appl. Phys. 29 (1958) 909.

[5] Thonemann P. C., Harrison E. R., AERE GP/R 1190 (1958).

[6] EYRICH W., Nukleonik 4 (1962) 167.

[7] VAL'TER A. K., Elektrostaticheskie uskoriteli zaryazhennykh chastits. (Gosatomizdat. Moskva), 1963. p. 230.

[8] NAGY J., ATOMKI Közl. 7 (1965) 209.

[9] PÁsztor E., et al. KFKI-71-47.

[10] Koltay E., Szalay A., ATOMKI Közl. 16 (1974) 181.
Koltay E., Mórik Gy., Somorjai E., ATOMKI Közl. 17 (1975) 131.

Kiss Á., Koltay E., Papp I., Szalay A., ATOMKI Közl. 1 (1976) 18.

[11] Bácskay Gy., Berecz I., Bódizs D., Kiss A., Koltay E., Papp I., Schadek J., Somorjai E., Szabó Gy., Szalay A., ATOMKI Közl. 11 (1969) 125.

[12] Kiss I., Koltay E., Szalay A., Shpak E. V., Nuclear Instrum. Methods. 107 (1973) 401.

[13] Marsicanin B. S., Nucl. Instrum. Methods. 75 (1969) 106.

[14] Billen J. H., Rev. Sci. Instrum. 46, No 1 (1975) 33.

[15] Conzett H. E., HaRvey B. G., Nucleonics 24, No 4 (1966) 48. 